\title{
FERRAMENTAS WEB 2.0 EM UNIDADES DE INFORMAÇÃO: ASPECTOS DE DIVULGAÇÃO E MELHORA CONTÍNUA IDENTIFICADOS EM ARTIGOS CIENTÍFICOS
}

\author{
WEB 2.0 TOOLS IN INFORMATION UNITS: ASPECTS OF \\ PROMOTION AND CONTINUOUS IMPROVEMENT \\ IDENTIFIED IN SCIENTIFIC PAPERS
}

Rodrigo Silva Peres ${ }^{a}$

Nysia Oliveira de Sáb

\begin{abstract}
RESUMO
Introdução: A evolução da internet e consequentemente do ambiente informático propiciou o surgimento das ferramentas Web 2.0, que por sua vez permitem a participação ativa dos usuários nos processos digitais. Objetivo: Identificar os tipos de interações que ocorrem nos blogs e no site de rede social Facebook, entre bibliotecários e usuários, para a divulgação e para a melhoria dos serviços e produtos oferecidos pelas bibliotecas universitárias. Metodologia: Com abordagem mista, artigos científicos foram analisados de duas maneiras. Quantitativamente com o auxílio da estatística descritiva para a identificação numérica dos que discorrem sobre o Facebook e sobre os blogs e, também, em relação à procedência geográfica dos campos empíricos. Para a análise qualitativa foi utilizada a técnica de análise de conteúdo nas categorias interação, uso e avaliação para posterior tratamento dos resultados. Resultados: Os resultados mostraram que a atenção por parte das bibliotecas em relação às ferramentas Web 2.0 é focada na utilização, seguida da avaliação, ficando a interação com os usuários minimizada. Conclusões: As unidades de informação estão conseguindo divulgar os seus produtos e serviços via internet, mas não estão fazendo o uso de todo o potencial que os usuários possuem para melhorar suas atividades e processos.
\end{abstract}

Descritores: Web 2.0. Interatividade. Unidades de Informação. Sites de redes sociais. Blogs.

\footnotetext{
a Bacharel em Biblioteconomia e Gestão de Unidades de Informação pela Universidade Federal do Rio de Janeiro (UFRJ). E-mail: rodrigo-sw1@hotmail.com

b Doutora em Políticas Públicas e Formação Humana pela Universidade do Estado do Rio de Janeiro (UERJ). Professora do Curso de Biblioteconomia e Gestão de Unidades de Informação da Universidade Federal do Rio de Janeiro (UFRJ). E-mail: nysia@facc.ufrj.br
} 


\section{INTRODUÇÃO}

A expansão das tecnologias da informação e comunicação (TIC) em diferentes áreas (acadêmica, comercial, jurídica) e seus usos vêm sendo ampliados exponencialmente ao redor do mundo, tanto pelas pessoas quanto pelas organizações.

Nesse cenário, uma das formas com que o desenvolvimento científico e tecnológico se faz presente na vida dos indivíduos e das empresas é pelo uso de ferramentas da Web 2.0. Essa web é entendida como o uso de todo o potencial disponibilizado pelas pessoas na internet, aumentando a comunicação, difundindo a interação e amplificando a colaboração. Especialmente duas mídias despertaram o interesse dos usuários, os blogs e os sites de redes sociais. A primeira por possibilitar às pessoas a expressão de suas opiniões, anteriormente restritas em relação ao alcance com o domínio dos meios de comunicação de massa. A segunda por permitir a comunicação em tempo real, além do acompanhamento multimídia por textos, fotos e vídeos de acordo com o interesse de cada pessoa.

$\mathrm{Na}$ visão do paradigma social da Ciência da Informação de Capurro (2003), o qual concebe os aspectos sociais como influenciadores nos processos informacionais, se encontram as bibliotecas que estão adicionando essas ferramentas sociais às suas atividades. Tais instituições, geralmente, têm o objetivo de comunicar as atividades realizadas para alcançarem cada vez mais usuários potenciais, que poderiam fazer parte do ambiente informacional, e se aproximarem dos usuários reais, os quais fazem uso regular dos serviços e produtos ofertados.

As bibliotecas na perspectiva de Maciel e Mendonça (2006) são um tipo de unidade de informação compostas de missão, visão, valores, planejamento, acompanhamento e pessoal capacitado para atingir os objetivos propostos. Logo, se faz necessária a aplicação desses conceitos administrativos para que as ferramentas de Web 2.0 sejam utilizadas de maneira adequada, explorando 
além da divulgação, a interação com os usuários para a melhora contínua dos serviços e produtos disponíveis.

Desse modo, o objetivo desse estudo é analisar se o uso das ferramentas da Web 2.0, especificamente o site de rede social Facebook e os blogs, na perspectiva da interação entre bibliotecários e usuários, contribui para a divulgação e para a melhoria dos serviços e produtos oferecidos pelas unidades de informação.

\section{INTERATIVIDADE}

Primo (2005) relata que o modelo transmissionista da informação ainda é muito influente, mas que embora a cadeia emissor-mensagem-canal-receptor possa ser suficiente para problemas técnicos de transmissão telefônica, é deficiente quando transportada para o contexto amplo da comunicação humana.

A questão, como destacam Capurro e Hjørland (2007), é que o modelo possui uma visão quantitativa da informação com uma perspectiva unilateral. Os autores alertam que nesse ambiente descrito nenhuma informação poderia ser transmitida, já que o foco não está em nenhuma mensagem significativa. Reforçando essa ideia, Russo (2010, p. 51) diz que "[...] essa teoria não se importava com o conteúdo ou a finalidade da informação, considerando-a como somente aqueles símbolos que são incertos para o receptor".

O termo "interatividade" para Lévy (1999) em geral ressalta a participação ativa do beneficiário de uma transação de informação, isto porque a possibilidade de reapropriação e de reconhecimento material da mensagem por seu receptor é um parâmetro fundamental para avaliar o grau de interação de um produto tecnológico.

Já na abordagem sistêmico-relacional Primo (2007) define as interações como a "ação entre" os participantes de um encontro ou a atuação de um agente em outro em relação de mutualidade, removendo o olhar do canal e dos polos extremos da comunicação e voltando-o para a bidirecionalidade, o fluxo de mãodupla de mensagens. 
Com essas questões sobre interatividade colocadas, Rafaeli (1998) pontua que apesar de nem todas as comunicações serem interativas, estas podem conter respostas coerentes e que a interatividade não é uma característica inerente aos meios ou canais, eles podem remover barreiras ou potencializar a comunicação, mas não são a interação em si.

A fim de melhor organizar as interações que ocorrem no ambiente informático, Primo (2007) sugere dois grandes grupos. O primeiro denominado de interação mútua, no qual existe a construção compartilhada do próprio relacionamento e de futuras problematizações por meio da recursividade da comunicação em que o comportamento é definido por ações anteriores. Devido a essa dinâmica e em virtude dos sucessivos desequilíbrios que impulsionam a transformação do sistema, esse tipo de interação é um constante "vir a ser", e sua construção jamais pode ser prevista. O outro é a interação reativa, essas interações dependem fortemente da automatização e da previsibilidade, são dados ao interagente algumas escolhas, levando-o a caminhos prédeterminados, que sendo alterados o sistema pode ser bruscamente interrompido. Ressaltamos que no trabalho em questão, a visão do conceito de interação a ser utilizado será a de Primo (2007).

\section{WEB 2.0}

A internet visou a troca de informações para o desenvolvimento da ciência e da tecnologia e a ascensão da web vislumbrou diversas possibilidades que poderiam ser proporcionadas, as pessoas, organizações e nações.

No entanto, após a quebra de várias empresas na área de tecnologia da informação, em 2001, Tim O'Reilly e Dale Dougherty, perceberam que empresas desse setor como Google, Yahoo, eBay e Amazon não tinham tido o mesmo destino. Analisando-as identificaram algumas características em comum, já que eram "[...] de natureza colaborativa, interativas, dinâmicas e a linha entre criação e consumo nesses ambientes era indistinta (usuários criavam o conteúdo desses sites tanto quanto o consumiam)" (IMRAM, 2011, p. 47-48). 
Nesta perspectiva, O'Reilly (2005) definiu a Web 2.0 como plataforma online dinâmica que possibilita a interação e a participação de diferentes atores no ambiente digital com o objetivo de criar e compartilhar informações. Explica, ainda, que primeiramente a ideia por trás da palavra não deve ser considerada uma novidade, mas sim como uma evolução que permite a utilização efetiva de todo o potencial disponível na web. Segundo que o conceito não possui fronteiras rígidas, sendo que diferentes sites e ferramentas atingem determinados indicadores de interatividade em variados aspectos e intensidades.

Com a rápida evolução e inovação dos softwares utilizados nas tecnologias da informação, é correto afirmar então que já existiam serviços Web 2.0 antes mesmo da definição do seu conceito e que o termo em si tem origem no entorno empresarial e forte teor de marketing (MARGAIX-ARNAL, 2007).

Dentre todas as características que compõem esse uso mais eficiente e eficaz das aplicações 2.0 da internet comercial, um deles se destaca devido à importância sobre os outros. Estamos falando da inteligência coletiva, definida por Lévy (2011) como o trabalho colaborativo de um grupo de indivíduos, que utilizando a comunicação e a interação poderá alcançar nível de conhecimento além da simples soma da capacidade cognitiva de cada pessoa envolvida no processo. Tal teoria é baseada na ideia de que o saber absoluto só pode ser alcançado com a integração de cada pessoa, mesmo que essa não tenha tido uma educação formal. Alvim (2011, p. 16) salienta que esse conceito "[...] exprime a ideia de que as tecnologias, na sociedade, são mediadoras entre as inteligências individuais e potencializam as suas capacidades criativas".

Na web 2.0 existem diferentes ferramentas que para Casey e Savastinuk (2007) podem ser agrupadas a partir de suas características comuns em: wikis, fontes RSS, mensagens instantâneas, blogs e sites de redes sociais, sendo as duas últimas o foco deste estudo devido a sua presença nas unidades de informação. 


\subsection{SITES DE REDEs Socials}

O foco das redes sociais é proporcionar aos indivíduos a gestão dos seus relacionamentos e torna-los visíveis aos outros. Recuero (2009) faz a diferenciação entre os softwares que servem como base para que as redes sociais ocorram efetivamente entre as pessoas e os sites de redes sociais que necessitam da interação entre indivíduos para serem considerados como tal.

Os sites de redes sociais permitem aos seus usuários compartilharem dados pessoais e conteúdos informacionais (textos, fotos e vídeos) e também a comunicação pela troca de mensagens e discussão de temáticas comuns em fóruns ou grupos. Boyd e Ellison (2007) definem esses sites como serviços baseados na web que possibilitam a construção de perfis públicos ou semipúblicos, criação de lista de amigos e a visualização e navegação pelas listas criadas por si próprio ou por outras pessoas, gerando assim mais conexões.

\subsection{FACEBOOK}

Esse website criado por Mark Zuckenberg, tinha como objetivo, inicialmente, evidenciar e promover a comunicação somente entre os discentes da Universidade de Harvard, cujo acesso foi ampliado devido ao sucesso da iniciativa para estudantes de outras universidades americanas e inglesas, sendo liberado para a sociedade como um todo em 2006. No entanto, este não é o primeiro site desse estilo na web, visto que a disponibilização dos seus antecessores para o público possui quase duas décadas. Boyd e Ellison (2007), apontam o SixDegrees.com que data de 1997, como sendo o primeiro site a possuir as características que potencializam uma rede social.

\subsection{BLOGS}

Uma das ferramentas da Web 2.0 que possibilita a produção em massa e descentralizada da informação são os blogs. Pontes (2013, p. 28), define os weblogs como um "[...] espaço virtual em que são escritos textos, inseridas 
imagens, ideias e entre outras possibilidades de expor conteúdos informacionais para uso e produção de conhecimento na sociedade".

Araújo (2010) propõe algumas categorizações para os blogs, classificando-os em pessoais (em forma de diários); de filtros (o autor seleciona informações do seu interesse e disponibiliza os links); temáticos (tratam de assuntos específicos); e corporativos (utilizados para colaboração dentro de organizações). Segundo a autora os blogs se tornaram sucesso porque podem ser vistos como uma ferramenta de liberdade de expressão, possibilitando a postagem de ideias e informações por pessoas que não tinham essa oportunidade previamente, com os meios de comunicação de massa. Acresce, ainda, que a maioria desses sites são gratuitos para os usuários. Outro aspecto positivo para Primo e Recuero (2003) é a facilidade de gestão e de publicação de conteúdo por grande parte das pessoas que não precisam ter conhecimento aprofundado da linguagem HTML visto que já está previamente estabelecida nos sistemas.

\section{BIBLIOTECAS UNIVERSITÁRIAS}

As unidades de informação são responsáveis pela aquisição, tratamento, organização, disseminação e mediação do uso das informações presentes nos mais variados suportes, se constituindo como fontes inesgotáveis do conhecimento, como por exemplo: museus, arquivos, centros de documentação, bibliotecas, entre outros.

Especificamente as bibliotecas universitárias possuem a missão de proporcionar acesso ao conhecimento como apoio as atividades de ensino, pesquisa e extensão existentes no meio acadêmico e utilizam para esse fim diversos serviços e produtos que são ofertados a comunidade. De acordo com Cunha (2010), mesmo que essas bibliotecas tenham obtido uma concorrência de peso com a internet e as bases de dados online, ainda são consideradas como a fonte principal de informação acadêmica confiável e aliadas às tecnologias são as que mais desenvolvem serviços e produtos inovadores, visto a incessante demanda dos pesquisadores. 
A utilização da mentalidade da Web 2.0 nas bibliotecas foi comentado pela primeira vez por Casey (2005) em seu blog "Library Crunch" com o nome de "Biblioteca 2.0", onde o autor propõe uma postura para a comunidade em que os usuários, a mudança constante e a avaliação contínua se tornem o foco do trabalho dos bibliotecários.

Maness (2006, p. 3, tradução nossa), em sua teoria da Biblioteca 2.0 define esse conceito como "a aplicação de interação, colaboração, e tecnologias multimídia baseadas em web para serviços e coleções de bibliotecas baseadas em web". A teoria está alicerçada em quatro elementos essenciais: centrada no usuário, com a possibilidade de oferecer uma experiência multimídia, socialmente rica e comunitariamente inovadora.

O conceito Biblioteca 2.0 derivado da Web 2.0 baseia-se nos seguintes princípios: a tecnologia é importante, mas não é tudo; o usuário deve ter um novo papel na elaboração e gestão dos conteúdos, e precisam de espaços que permitam a sua participação; biblioteca 2.0 é uma referência aos serviços e a coleção; tem relação com o entorno virtual e também com o físico; para ser um bibliotecário 2.0, a de se perder o medo das tecnologias e de inovar (MARGAIXARNAL, 2007). O autor define a biblioteca 2.0 como "[...] a aplicação das tecnologias e da filosofia da web 2.0 às coleções e serviços bibliotecários, tanto no entorno virtual como no real" (2007, p. 102, tradução nossa)

Nessa linha, é entendido que os serviços 2.0 já são uma realidade, mas que o seu futuro desenvolvimento dependerá da capacidade dos bibliotecários se adaptarem as novas formas de comunicação, inovação, domínio das tecnologias e das ferramentas sociais que poderão ser ofertados.

\section{METODOLOGIA}

Para a realização dessa pesquisa a abordagem selecionada foi a mista, aplicando métodos qualitativos e quantitativos aos dados coletados (CRESWELL, 2010). Já com relação aos objetivos, possui caráter exploratório. 
Para embasar o referencial teórico foi utilizado o procedimento denominado de revisão bibliográfica para a discussão dos termos interatividade, Web 2.0 e bibliotecas universitárias.

A metodologia se constitui em duas outras fases: coleta dos artigos científicos e a sua posterior análise. Para a coleta dos dados a técnica empregada foi a pesquisa bibliográfica, buscando na literatura, artigos científicos que descrevessem a experiência do uso do site de rede social Facebook ou dos blogs em bibliotecas universitárias. A pesquisa foi feita nas seguintes bases de dados: Base de Dados Referenciais de Artigos de Periódicos em Ciência da Informação (BRAPCI); Library and Information Science Abstracts (LISA); e Information Science \& Technology Abstracts (ISTA).

O período da amostra compreendeu uma década, com início em 2006, ano em que foi publicado o artigo "Library 2.0 Theory: Web 2.0 and Its Implications for Libraries", do bibliotecário pesquisador estadunidense Maness (2006), sendo o ano limite 2015.

Após a seleção dos resumos a amostra foi analisada em duas partes, identificou-se com o auxílio da estatística descritiva a quantidade de artigos encontrados, quantos discorrem sobre o Facebook e sobre os blogs e a procedência geográfica dos campos empíricos abordados. Para o exame qualitativo utilizou-se análise de conteúdo na perspectiva de Bardin (1977), estabelecendo previamente três categorias: interação, uso e avaliação para posterior tratamento dos resultados, com a inferência e a interpretação.

\section{RESULTADOS}

Após o processo de seleção foram recuperados 18 artigos, sendo que a referência de cada artigo se encontra no Apêndice.

Após a leitura dos artigos foram removidos aqueles que tratavam simultaneamente do blog ou do Facebook em conjunto com outras ferramentas da Web 2.0, pois poderiam alterar a análise dos resultados, ficando a amostra final com oito artigos. 
Destes oito, 62\% (5) tratam exclusivamente da utilização do Facebook em bibliotecas universitárias: Cardoso, Silva, Lima e Costa (2015); Sachs, Eckel e Langan (2011); Ganster e Schumacher (2009); Houk e Thornhill (2013); Ofili e Emwanta (2014), 38\% (3) discutem por sua vez a aplicação dos blogs em bibliotecas universitárias: Santos e Rocha (2012); Chan e Cmor (2009); Sapp e Cogdill (2010). No que se refere à origem $50 \%$ (4) são estudos realizados em bibliotecas universitárias estadunidenses, 25\% (2) no Brasil, um da China 12,5\% (1) e outro da Nigéria $12,5 \%$ (1).

Distribuindo o campo empírico em relação ao tipo de ferramentas Web 2.0, obtivemos 5 artigos sobre o Facebook, filtrando pela localização da universidade temos 60\% (3) dos Estados Unidos da América, 20\% (1) do Brasil e outros $20 \%$ (1) da Nigéria. Já em relação aos blogs, temos três trabalhos com $33,3 \%$ para cada biblioteca em um país diferente: Brasil, China e Estados Unidos.

Nessa etapa os oito artigos foram analisados qualitativamente, por meio da análise de conteúdo nas categorias estabelecidas previamente e são apresentados por tipo de ferramenta: Facebook e blogs.

Como já informado, são 5 os artigos que mencionam de alguma maneira a questão da utilização do Facebook pelas bibliotecas, como por exemplo o artigo de Cardoso, Silva, Lima e Costa (2015) da Biblioteca de Referência do Núcleo de Estudos Afro-brasileiros da Universidade do Estado de Santa Catarina. Nele o autor informa que criou uma página no site de rede social em 2013 com o objetivo de divulgar e dar visibilidade aos serviços e produtos oferecidos pela unidade, assim como incentivar o empréstimo de livros do acervo e a leitura de documentos sobre a temática africana, afro-brasileira e indígena. Para tanto, postou-se "livros do acervo contendo foto, título, nome do autor e um pequeno resumo sobre os mesmos". Posteriormente, a divulgação dos livros no formato PDF possibilitou que os usuários fizessem download de obras. (CARDOSO; SILVA; LIMA; COSTA, 2015, p. 36).

Já Sachs, Eckel e Langan (2011) decidiram estabelecer uma presença digital na biblioteca ao observarem o grande índice de utilização dos sites de 
redes sociais por parte tanto dos usuários como dos próprios profissionais da unidade. Tal iniciativa tinha três objetivos principais: promover os recursos e serviços da biblioteca, ofertar serviço de referência virtual e divulgar dicas de pesquisa de modo assíncrono. As funcionalidades do Facebook permitiram que a unidade divulgasse e se aproximasse dos usuários. Tais funcionalidades "incluem atualização de status, notas, links e a possibilidade de criação de eventos. Quaisquer atualizações desses recursos são automaticamente enviadas para os 'amigos' da Biblioteca Waldo". (SACHS; ECKEL; LANGAN, 2011, p. 3, tradução nossa).

Também existem conexões entre a página mantida e outros recursos da biblioteca, como campos de pesquisa conectados com o catálogo online e a opção de enviar uma solicitação direto para o e-mail institucional. Para os autores a atualização da página e das funcionalidades permite que a biblioteca mantenha presença consistente em um ambiente frequentado pelos usuários.

Ganster e Schumacher (2009), em 2007, iniciaram o planejamento da criação de uma página no Facebook para as bibliotecas da Universidade Estadual de Nova lorque em Buffalo com a intenção de divulgar as unidades, seus serviços e produtos para toda a comunidade acadêmica e também proporcionar um local em que os usuários pudessem interagir com os bibliotecários (comunidade virtual). Assim, [...] "por meio da página nós podemos facilmente promover recursos e enviar atualizações para nossos fãs. (GANSTER; SCHUMACHER, 2009, p. 123, tradução nossa).

Os autores entendem que em sites de bibliotecas as informações não ficam tão visíveis, mas no site de rede social é possível estabelecer uma área mais visível para acessar informação, entre outros benefícios como pesquisar no catálogo online, compartilhar conteúdos de outras locais e obter outras informações da biblioteca como a hora e os dias de funcionamento.

Houk e Thornhill (2013) realizaram previamente uma pesquisa para saber se utilizar o Facebook seria útil para a unidade de informação. O resultado demonstrou que os usuários quase faziam uso diário dessa ferramenta e essas pessoas ranquearam o que gostariam de receber de uma página de biblioteca 
em relação ao conteúdo. Notícias da biblioteca, novidades sobre recursos informacionais e links diretos para bases de dados como PubMed e Medline ficaram no topo. Ressalte-se que foi criada uma equipe para especificamente administrar a página da Biblioteca Hirsch da Universidade de Tufts.

Ofili e Emwanta (2014) comentam que a iniciativa de usar o Facebook veio a partir de observações que mostravam os benefícios do site de rede social para as bibliotecas. Com isso, a Biblioteca John Harris da Universidade de Benin criou uma página e um grupo no site visando promover a unidade e disseminar informação. "O grupo foi criado com a intenção de fomentar a disseminação e facilitar a comunicação entre os bibliotecários e a comunidade, e também de servir de um meio de fácil comunicação entre os profissionais da biblioteca." (OFILI; EMWANTA, 2014, p. 196, tradução nossa).

Inicialmente o acesso ficou restrito à equipe da biblioteca visando a comunicação e a troca de informações oficiais entre as pessoas. No entanto, posteriormente, considerando que a troca de informações seria de interesse da comunidade foi aberto ao público um mês após sua criação.

Diferentemente da categoria anterior em que todos os artigos tinham algum conteúdo sobre utilização do Facebook em bibliotecas, no que se refere à interação somente três dos cinco artigos tratam desse tema e nem todos foram positivos.

"Nós tivemos alguma experiência com alunos solicitando serviço de referência ou instruções, mas isso foi tão infrequente que ficou claro para nós que o Facebook tinha valor limitado para esses tipos de interações". (SACHS; ECKEL; LANGAN, 2011, p. 22, tradução nossa). Neste caso, de acordo com as autoras o Facebook da unidade não conseguiu atingir esse objetivo.

O resultado dos estudos de Ganster e Schumacher (2009), demonstraram que um número significativo de estudantes do ensino médio e de fora dos Estados Unidos são grupos alvo para recrutamento da universidade. Assim, a página das bibliotecas representa para os estudantes um ambiente acessível e aberto para interação. 
O objetivo de Houk e Thornhill (2013) era avaliar como algumas variáveis afetam o engajamento, um sinônimo de interação, dos usuários. Alguns dos tópicos estudados foram a frequência das postagens, tipo de postagem, hora do dia e dia da semana. Outros dados analisados foram insights sobre os usuários e interações no Facebook, já que medem os conteúdos por visões diferentes. Enquanto os insights dos usuários apresentam visão mais generalizada, os insights das interações demonstram dados mais focados, como curtidas, comentários e citações.

A avaliação é uma questão percebida em todos os artigos sobre Facebook, adotando-se metodologias variadas para avaliar a experiência de uso do site de rede social nas bibliotecas.

Cardoso, Silva, Lima e Costa (2015) comparou, para avaliação, o período de empréstimo relativo a um ano antes da criação da página e os dados de empréstimo obtidos após um ano de criação da página da biblioteca, sendo que os resultados demonstraram que o "[...] número de empréstimos efetuados pela Biblioteca aumentou após a criação do perfil, contudo este aumento não foi estatisticamente significativo" (CARDOSO; SILVA; LIMA; COSTA, 2015, p. 36). Os autores acreditam que possivelmente o tempo de avaliação para verificar a influência da página no número de empréstimos não foi suficiente.

Outro estudo, por meio de uma pesquisa com 136 usuários da unidade de informação avaliou a efetividade do Facebook como ferramenta de marketing, referência e orientação, além do conforto e satisfação com a presença da biblioteca no site de rede social. Como resultado Sachs, Eckel e Langan (2011) indicaram que a maioria dos respondentes concorda que o site de rede social é um meio útil e interativo de conhecer sobre os produtos e serviços da biblioteca.

Identificar as melhores práticas de postagem com base nos dados disponibilizados pelo site da rede social foi a opção para avaliação adotada no estudo de Houk e Thornhill (2013), pois foi encontrada "[...] correlação positiva que sugere que o aumento na frequência de postagens está relacionada com o aumento do engajamento dos usuários e encoraja que os mesmos curtam a página." (HOUK; THORNHILL, 2013, p. 379, tradução nossa). Outro ponto 
observado foi que o tipo de postagem interfere no volume de interação dos usuários e aqueles conteúdos que aparecem com fotos e vídeos tem um impacto maior do que as postagens que só possuem texto. Por outro lado, foi visto que o dia da semana e a hora da postagem não interferem no engajamento dos usuários.

Outro estudo procurou analisar, por meio de questionário aplicado a 49 membros do corpo técnico da biblioteca, se o site de rede social é uma ferramenta útil para ser usada como serviço de disseminação de informação. $\mathrm{Na}$ visão dos pesquisadores, a página "[...] provou ser uma ferramenta profissional para disseminar a biblioteca, comunicar com os técnicos e usuários, e disseminar serviços de informação." (OFILI; EMWANTA, 2014, p. 201, tradução nossa). Para os autores a criação de um grupo no Facebook foi positiva pois cria um ambiente favorável para todas as formas de comunicação de informação, sem barreiras hierárquicas ou de localização.

No entanto, nem todos as pesquisas consideraram a etapa de avaliação dessa ferramenta de forma aprofundada, indicando somente que há a possibilidade de um acompanhamento estatístico pois "[...] com os insights da página, gestores podem observar estatísticas da página, incluindo demografia dos seus usuários, visualizações da página, e o aumento de fãs." (GANSTER; SCHUMACHER, 2009, p. 120, tradução nossa).

Os três artigos que tratam dos Blogs (SANTOS; ROCHA, 2012; CHAN; CMOR, 2009; SAPP; COGDILL, 2010) mencionam a questão da utilização da ferramenta por parte das bibliotecas universitárias.

No estudo de Santos e Rocha (2012) focado na Biblioteca Lydio Bandeira de Mello da Faculdade de Direito da UFMG, o blog tinha como objetivo ser um canal de comunicação entre a biblioteca e seus usuários. Todo o conteúdo das postagens é inserido pelas autoras e possui colaboração do restante da equipe da biblioteca, que envia sugestões de temas. No início a periodicidade era de uma postagem por dia, depois passou para uma regularidade de quatro postagens por semana ou de acordo com as novidades da biblioteca e eventos realizados na instituição. 
A ferramenta foi avaliada em relação à sua aceitação perante a comunidade acadêmica basicamente de duas maneiras. Quantitativamente por meio da ferramenta estatística disponibilizada pelo Wordpress (software livre e gratuito que serve como plataforma de comunicação), e qualitativamente pelos comentários. Foi possível, por meio da análise quantitativa, descobrir a média de visitas por dia e também quais eram os conteúdos mais acessados, sendo a "postagem atual", o com mais acesso, o que se justifica por ser a primeira visualizada quando um usuário acessa a página, o segundo foi o número de acesso às páginas das bases de dados, o que se explica por possibilitar a busca por assunto.

No que se refere à abordagem qualitativa, a maioria das respostas com base nos comentários foi positiva, onde alguns usuários ficaram sabendo de treinamentos que iriam ocorrer fisicamente na biblioteca, e que alguns só acessam as bases pelos links do blog, já que a página da unidade de informação no site da instituição se encontra desatualizada (SANTOS; ROCHA, 2012).

Já o artigo de Chan e Cmor (2009) discorre sobre a criação de um blog da Biblioteca da Universidade Batista de Hong Kong para desenvolver a competência em informação nos alunos de uma disciplina do primeiro ano de graduação do curso de Ciência Política. Os bibliotecários aproveitaram o blog para encorajar os estudantes à solicitaram ajuda não só para responderem as perguntas, mas também para qualquer outro tipo de trabalho e projeto em que eles estivessem atuando.

Para avaliação dessa ferramenta foi elaborado questionário respondido por 76 dos 88 discentes que participaram da experiência com o blog, sendo considerado três aspectos: qualidade das respostas dos alunos; uso do blog além do mínimo necessário; opinião dos estudantes sobre a utilidade do blog. A avaliação das respostas foi feita com a equipe responsável pelo blog e o docente da disciplina, verificando-se que "A qualidade geral das respostas foi sólida, com 53 estudantes dando respostas classificadas como boas ou excelentes. Outros 16 ficaram com satisfatório, deixando $19 \mathrm{com}$ precisa de melhorias." (CHAN; CMOR, 2009, p. 400, tradução nossa). 
$\mathrm{Na}$ etapa do planejamento do blog, se tinha receio de que os estudantes acessassem o site somente para realizar a sua tarefa semanal. Isso se provou ser menos recorrente do que o esperado, com somente $20 \%$ dos respondentes afirmando que só fizeram as visitas demandadas pelo docente.

Outro resultado foi que a maioria dos estudantes concordaram que o blog os ajudou em três áreas: aprender sobre os recursos da biblioteca; aprender sobre estratégias de busca; e se sentir confortável em usar os recursos da biblioteca. Esses resultados indicam que a maioria dos alunos sentiram que 0 blog foi útil para o seu aprendizado, tanto em relação a sua própria competência em informação, como também ajudando com o trabalho final da disciplina. Entretanto Chan e Cmor (2009) ressaltam as limitações do projeto e dos resultados, que refletem somente uma disciplina de uma universidade, não podendo ser usado para generalizações.

O trabalho de Sapp e Cogdill (2010) descreve um blog da biblioteca do Centro de Ciências da Saúde da Universidade do Texas em San Antonio que foi planejado para promover acesso às informações biomédicas e de saúde para a população e profissionais dessa área, incluindo os desafios associados à linguagem e diferenças culturais, desigualdade de status de saúde e acesso à planos.

No aspecto da interação Santos e Rocha (2012) comentam que os bibliotecários receberam elogios, opiniões e reclamações dos usuários após a implantação do blog na unidade de. Um exemplo sobre a participação dos usuários foi o número elevado de respostas sobre a postagem que apresentava uma base de dados jurídica e fornecia senha de acesso gratuito para avaliação da comunidade.

Para avaliar o nível de interatividade os autores Chan e Cmor (2009) perguntaram inicialmente aos usuários na perspectiva da competência em informação sobre recuperação de artigos em bases de dados, não havendo interação significativa com os bibliotecários. Após orientação dos bibliotecários para esclarecimento de dúvidas, os níveis de interação se elevaram, sendo que 
estes procuram compartilhar o que aprenderam com os colegas, ações que na visão dos autores são raras e de grande valor para os bibliotecários e professor.

Outro artigo também apresenta a opção por análises avaliativas tanto quantitativa quanto qualitativas do blog. Para a análise quantitativa foram utilizadas duas ferramentas para coleta de dados, WebTrends (coleta e análise do número de visitantes e da sua atividade no interior da ferramenta) e AWStats (coleta de informações adicionais a respeito de como os usuários navegam pelo blog). As autoras comentam que embora o número de postagens tenha decrescido, o número geral de acessos aumentou, o que se pode considerar como aumento de interesse por parte do público. Aspectos relativos às interações com os usuários também foram abordados, mas os resultados apresentados não foram considerados satisfatórios. De acordo com Sapp e Cogdill (2010) a análise qualitativa da utilidade do blog com seus colaboradores de conteúdo identificou desafios para encontrar informações atualizadas e relevantes para postarem e, para tentar solucionar essa questão os autores estão utilizando ferramentas de etiquetagem social que servem para indexação, armazenamento, gestão e compartilhamento em uma fonte centralizada.

Após as análises dos artigos com base nas categorias previamente selecionadas são apresentadas as considerações da pesquisa.

\section{CONSIDERAÇÕES}

Ao longo da pesquisa foi observado se as bibliotecas universitárias que estão fazendo uso das ferramentas Web 2.0, especialmente do site de rede social Facebook e dos blogs, também estão atentas para as questões da interação com os usuários e da avaliação crítica do sucesso dos projetos.

Constatou-se que o foco dos autores está concentrado na utilização das ferramentas, seguido da avaliação, ficando a interação em patamar inferior em comparação com os outros aspectos. Acresce, ainda, que todas as bibliotecas da amostra tentaram utilizar tanto o Facebook quanto os blogs embasadas em pesquisas científicas, buscando entender as reais necessidades dos seus usuários e fazendo uso de técnicas de planejamento e curadoria de conteúdo. 
Com relação à avaliação, várias foram as metodologias adotadas para verificar a efetividade e utilidade dos projetos, desde estratégias quantitativas aplicadas em estatísticas de uso de sites até modos qualitativos que buscaram entender os desafios e perspectivas por parte dos colaboradores de um blog em levar material relevante para o seu público.

A interação, como dito anteriormente, foi a categoria analisada que menos despertou interesse dos autores, e nem todos os resultados encontrados pelos autores foram positivos. Em alguns casos, o Facebook não foi considerado útil para troca de informações entre as unidades de informação e os seus usuários; já em outros foi verificado a possibilidade de comunicação positiva entre as pessoas e os profissionais da informação.

Identificou-se que a utilização planejada e a avaliação das ferramentas possibilitam que as bibliotecas consigam alcançar públicos maiores do que os habituais, servindo desse modo para divulgação dos diversos tipos de serviços, produtos e atividades que são ofertados pelas unidades. Já a consequência da baixa interação recai na questão da participação incipiente dos usuários, que no máximo reagem as postagens sem se engajar profundamente nos assuntos. Desse modo, a própria unidade de informação - sem a participação ativa das pessoas - não consegue usar os comentários, críticas e sugestões para melhorar o trabalho realizado.

Assim, considerando os resultados elencamos algumas recomendações, visando o uso efetivo por parte das bibliotecas universitárias das ferramentas Facebook e blogs: elaborar planejamento para implantação considerando a realização de estudo de usuários e desenvolver plano de marketing para divulgar o novo canal da biblioteca. Outros aspectos a serem observados são a realização do trabalho de forma compartilhada, promoção de conteúdo multimídia e atualizado, monitoramento das atividades dos usuários na página levando sempre em conta o zelo pela privacidade dos mesmos e por fim, a avaliação constante do projeto visando medir a efetividade das ferramentas para a unidade de informação. 
Ressalta-se que bibliotecários devem procurar utilizar as ferramentas disponíveis na Web 2.0, tendo em vista seu uso cada vez mais frequente pelos usuários no seu dia a dia, de forma que possam contribuir para ampliar serviços e produtos da biblioteca.

Por fim, tendo por base essa temática sugere-se a sua ampliação considerando outros tipos de unidades de informação, assim como investigar se bibliotecários estão utilizando ferramentas Web 2.0 para compartilhar informação e discutir ideias, oportunidades e desafios a respeito da sua profissão.

\section{REFERÊNCIAS}

ALVIM, L. Impossível não estar no Facebook!: o nascimento das bibliotecas portuguesas na rede social. Cadernos de Biblioteconomia, Arquivística e Documentação, Lisboa, v. 1, p. 14-26, 2011. Disponível em: http://www.bad.pt/publicacoes/index.php/cadernos/article/view/737. Acesso em: 24 mar. 2016.

ARAÚJO, P. C. O blog "na era da informação" como ferramenta de compartilhamento de informação, conhecimento e para a promoção profissional. Revista ACB: Biblioteconomia em Santa Catarina, Florianópolis, v. 15, n. 1, p. 201-213 jan./jun., 2010. Disponível em: http://revista.acbsc.org.br/index.php/racb/article/view/676/pdf_26. Acesso em: 20 fev. 2016.

BARDIN, L. Análise de conteúdo. Lisboa: Edições 70, 1977.

BOYD, D.; ELLISON, N. Social network sites: definition, history, and scholarship. Journal of Computer-Mediated Communication, Indiana, v. 13, n. 1, 2007. Disponível em: http://jcmc.indiana.edu/vol13/issue1/boyd.ellison.html. Acesso em: 12 jun. 2016.

CAPURRO, R. Epistemologia e ciência da informação. In: ENCONTRO NACIONAL DE PESQUISA EM CIÊNCIA DA INFORMAÇÃO, 5., 2003, Belo Horizonte. Anais [...]. Belo Horizonte: Associação Nacional de Pesquisa e PósGraduação em Ciência da Informação e Biblioteconomia, 2003. Disponível em: http://www.capurro.de/enancib_p.htm. Acesso em: 16 jun. 2016.

CAPURRO, R.; HJØRLAND, B. O conceito de informação. Perspectivas em Ciência da Informação, Belo Horizonte, v. 12, n. 1, p. 148-207, jan./abr. 2007. Disponível em: http://www.scielo.br/pdf/pci/v12n1/11.pdf. Acesso em: 2 jun. 2016. 
CARDOSO, P.; SILVA, F. G.; LIMA, G.; COSTA, A. Utilização do Facebook como meio de divulgação de fontes de informação pela Biblioteca de Referência NEAB/UDESC. Revista ACB, Florianópolis, v. 20, n. 1, p. 34-40, abr. 2015. Disponível em: https://revista.acbsc.org.br/racb/article/view/977. Acesso em: 2 dez. 2016.

CASEY, M. What Library 2.0 is not. LibraryCrunch, [S. I.: s. n.], 2005. Disponível em:

http://www.librarycrunch.com/2005/10/what_library_20_is_not.html. Acesso em: 20 maio 2016.

CASEY, M.; SAVASTINUK, L. Library 2.0: a guide to participatory library service. New Jersey: Information Today, 2007.

CHAN, C.; CMOR, D. Blogging toward information literacy: engaging students and facilitating peer learning. Reference Services Review, v. 37, n. 4, p. 395407, 2009. Disponível em:

http://repository.hkbu.edu.hk/cgi/viewcontent.cgi?article=1001\&context=lib_ja. Acesso em: 20 maio 2016.

CRESWELL, J. W. Projeto de pesquisa: métodos qualitativo, quantitativo e misto. 3. ed. Porto Alegre: Artmed, 2010.

CUNHA, M. B. A biblioteca universitária na encruzilhada. DataGramaZero: Revista de Ciência da Informação, Rio de Janeiro, v. 11, n. 6, dez. 2010. Disponível em: http://www.dgz.org.br/dez10/Art_07.htm. Acesso em: 18 maio 2016.

GANSTER, L.; SCHUMACHER, B. Expanding beyond our library walls: building an active online community through Facebook. Journal of Web Librarianship, v. 3, n. 2, p. 111-128, jun. 2009. Disponível em:

http://www.tandfonline.com/doi/abs/10.1080/19322900902820929. Acesso em: 22 maio 2015.

HOUK, K.; THORNHILL, K. Using Facebook page insights data to determine posting best practices in an academic health sciences library. Journal of Web Librarianship, v. 5, n. 2, p. 372-388, dez. 2013. Disponível em: http://www.tandfonline.com/doi/abs/10.1080/19322909.2013.837346. Acesso em: 14 set. 2016.

LÉVY, P. A inteligência coletiva: por uma antropologia do ciberespaço. 8. ed. São Paulo: Edições Loyola, 2011.

LÉVY, P. Cibercultura. São Paulo: 34, 1999.

MACIEL, A. C.; MENDONÇA, M. A. R. Bibliotecas como organizações. 2. ed. Rio de Janeiro: Interciência, 2006. 
MANESS, J. M. Library 2.0 theory: web 2.0 and its implications for libraries. Webology, v. 3, n. 2, jun. 2006. Disponível em: http://www.webology.org/2006/v3n2/a25.html. Acesso em: 25 jul. 2016

MARGAIX-ARNAL, D. Conceptos de Web 2.0 y Biblioteca 2.0: origen, definiciones y retos para las bibliotecas actuales. EI Profesional de la Información, v. 16, n. 2, p. 95-106, mar./abr. 2007. Disponível em: http://eprints.rclis.org/archive/00009785. Acesso em: 11 maio 2008.

O'REILLY, T. What is Web 2.0: design patterns and business models for the next generation of software. O'Reilly Media: Sebastopol, 2005. Disponível em: https://www.oreilly.com/pub/a/web2/archive/what-is-web-20.html.Acesso em: 17 mar. 2016.

OFILI, D. N.; ENWANTA, M. Facebook as an information service delivery tool: perspectives of library staff at the University of Benin, Nigeria. African Journal of Library, Archives and Information Science, v. 24, n. 2, p. 195-202, out. 2014. Disponível em: http://www.ajol.info/index.php/ajlais/article/view/135074. Acesso em: 11 maio 2016.

PONTES, V. P. El contexto informacional del blog para la diseminación de la información: un análisis teórico. Biblios: revista de bibliotecología y ciencias de la información, Lima, n. 52, p. 27-34, abr./jun., 2013. Disponível em:

http://biblios.pitt.edu/ojs/index.php/biblios/article/view/101. Acesso em: 28 maio 2016.

PRIMO, A. Enfoques e desfoques no estudo da interação mediada por computador. 404NotFound, n. 45, 2005. Disponível em:

http://www.ufrgs.br/limc/PDFs/enfoques_desfoques.pdf. Acesso em: 22 maio 2016.

PRIMO, A. Interação mediada por computador: comunicação, cibercultura, cognição. Porto Alegre: Sulina, 2007.

PRIMO, A.; RECUERO, R. Hipertexto cooperativo: uma análise da escrita coletiva a partir dos Blogs e da Wikipédia. Revista FAMECOS: mídia, cultura e tecnologia, Porto Alegre, v. 10, n. 22, 2003. Disponível em:

http://revistaseletronicas. pucrs.br/ojs/index.php/revistafamecos/article/view/323 5/2496. Acesso em: 20 maio 2016.

RAFAELI, S. Interactivity: from new media to communication. In: Sage annual review of communication research: advancing communication science. Beverly Hills: Sage, 1988. p. 110-134.

RECUERO, R. Redes sociais na internet. Porto Alegre: Sulina, 2009.

RUSSO, M. Fundamentos em Biblioteconomia e Ciência da Informação. Rio de Janeiro: E-papers, 2010. 
Ferramentas web 2.0 em unidades de informação: aspectos de divulgação e melhora contínua identificados em artigos científicos

SACHS, D.; ECKEL, E. J.; LANGAN, K. A. Striking a balance: effective use of Facebook in an academic library. Internet Reference Services Quarterly, v. 16, n. 1-2, p. 35-54, 2011. Disponível em:

http://scholarworks.wmich.edu/cgi/viewcontent.cgi?article=1018\&context=library _pubs. Acesso em: 22 May 2016.

SANTOS, E. L.; ROCHA, S. M. O blog como ferramenta de comunicação entre a biblioteca e seus usuários: a experiência da biblioteca Lydio Bandeira de Mello, da Faculdade de direito da Universidade Federal de Minas Gerais.

Encontros Bibli: Revista Eletrônica de Biblioteconomia e Ciência da Informação, Florianópolis, v. 17, n. 33, p. 134-152, abr. 2012. Disponível em: https://periodicos.ufsc.br/index.php/eb/article/view/1518-2924.2012v27n33p134. Acesso em: 2 ago. 2016.

SAPP, L.; COGDILL, K. Blogging in support of health information outreach. Medical Reference Services Quarterly, v. 29, n. 3, p. 240-248, 2010. Disponível em: http://www.tandfonline.com/doi/abs/10.1080/02763869.2010.494488. Acesso em: 22 maio 2016.

\section{APÊNDICE A - Artigos recuperados nas bases de dados}

\begin{tabular}{|c|l|}
\hline$N^{0}$ & \multicolumn{1}{|c|}{ REFERÊNCIA } \\
\hline 1. & $\begin{array}{l}\text { ALONSO-AREVALO, J.; CORDÓN-GARCIA, J.; GOMEZ-DIAZ, R.; GARCIA- } \\
\text { DELGADO-GIMENEZ, B. Uso y aplicación de herramientas 2.0 en los servicios, } \\
\text { producción, organización y difusión de la información en la biblioteca } \\
\text { universitária. Investigación Bibliotecológica, v. 28, n. 64, p. 51-74, 2014. }\end{array}$ \\
\hline 2. & $\begin{array}{l}\text { CARDOSO, P.; SILVA, F. G.; LIMA, G.; COSTA, A. Utilização do Facebook } \\
\text { como meio de divulgação de fontes de informação pela Biblioteca de Referência } \\
\text { NEAB/UDESC. Revista ACB, Florianópolis, v. 20, n. 1, p. 34-40, abr. 2015. }\end{array}$ \\
\hline 3. & $\begin{array}{l}\text { CHAN, C.; CMOR, D. Blogging toward information literacy: engaging students } \\
\text { and facilitating peer learning. Reference Services Review, v. 37, n. 4, p. 395- } \\
\text { 407, 2009. }\end{array}$ \\
\hline 4. & $\begin{array}{l}\text { CHASE, D. Using online social networks, podcasting, and a blog to enhance } \\
\text { access to Stony Brook University Health Sciences Library resources and } \\
\text { services. Journal of Electronic Resources in Medical Libraries, v. 5, n. 2, p. } \\
\text { 123-132, 2008. }\end{array}$ \\
\hline 5. & $\begin{array}{l}\text { GANSTER, L.; SCHUMACHER, B. Expanding beyond our library walls: building } \\
\text { an active online community through Facebook. Journal of Web Librarianship, } \\
\text { v. 3, n. 2, p. 111-128, Jun. 2009. }\end{array}$ \\
\hline 6. & $\begin{array}{l}\text { GOLDERMAN, G. M.; CONNOLLY, B. Infiltrating NetGen cyberculture: strategies } \\
\text { for engaging and educating students on their own terms. The Serials Librarian, } \\
\text { v. 53, n. 3, p. 165-182, out. 2008. }\end{array}$ \\
\hline 7. & $\begin{array}{l}\text { HOUK, K.; THORNHILL, K. Using Facebook page insights data to determine } \\
\text { posting best practices in an academic health sciences library. Journal of Web } \\
\text { Librarianship, v. 5, n. 2, p. 372-388, Dec. 2013. }\end{array}$ \\
\hline
\end{tabular}


Ferramentas web 2.0 em unidades de informação: aspectos de divulgação e melhora contínua identificados em artigos científicos

MACK, D.; BEHLER, A.; ROBERTS, B.; RIMLAND, E. Reaching Students with

8. Facebook: Data and Best Practices. Electronic Journal of Academic and Special Librarianship, v. 8, n. 2, p. 1-7, 2007.

OFILI, D. N.; ENWANTA, M. Facebook as an information service delivery tool:

9. perspectives of library staff at the University of Benin, Nigeria. African Journal of Library, Archives and Information Science, v. 24, n. 2, p. 195-202, out. 2014.

OLIVEIRA, E. D.; PAULA, M. G.; MACULAN, B. C. M. S. A tecnologia RSS no

10. serviço de referência da Biblioteca Etelvina Lima da UFMG. Revista Brasileira de Biblioteconomia e Documentação, v. 11, n. esp., 2015.

PACE, A. L.; MCGEE, M. Meeting students where they are: enhancing the

11. library's physical and virtual presence at High Point University. North Carolina Libraries, v. 68, n. 2, p. 15-17, 2010.

PALMER, S. Characterizing university library use of social media: a case study of

12. Twitter and Facebook from Australia. The Journal of Academic Librarianship, v. 40, n. 6, p. 611-619, nov. 2014.

RAM, S.; ANBU, J. P. K.; KATARIA, S. Responding to user's expectation in the

13. library: innovative Web 2.0 applications at JUIT Library. Program: electronic library and information systems, v. 45, n. 4, p. 452-469, 2011.

SACHS, D.; ECKEL, E. J.; LANGAN, K. A. Striking a balance: effective use of

14. Facebook in an academic library. Internet Reference Services Quarterly, v. 16, n. 1-2, p. 35-54, 2011.

SANTOS, E. L.; ROCHA, S. M. O blog como ferramenta de comunicação entre a biblioteca e seus usuários: a experiência da biblioteca Lydio Bandeira de Mello,

15. da Faculdade de direito da Universidade Federal de Minas Gerais. Encontros

Bibli: Revista Eletrônica de Biblioteconomia e Ciência da Informação,

Florianópolis, v. 17, n. 33, p. 134-152, abr. 2012

16. SAPP, L.; COGDILL, K. Blogging in support of health information outreach.

Medical Reference Services Quarterly, v. 29, n. 3, p. 240-248, 2010.

VUCOVICH, L. A.; GORDON, V. S.; MITCHELL, N.; ENNIS, L. A. Is the time and

17. effort worth it? one library's evaluation of using social networking tools for

outreach. Medical Reference Services Quarterly, v. 32, n. 1, p. 12-25, fev. 2013.

XIAO, N. Web 2.0 as catalyst: virtually reaching out to users and connecting

18. them to library resources and services. Issues in Science and Technology

Librarianship, n. 55, p. 1-8, 2008.

\title{
WEB 2.0 TOOLS IN INFORMATION UNITS: ASPECTS OF PROMOTION AND CONTINUOUS IMPROVEMENT IDENTIFIED IN SCIENTIFIC PAPERS
}

\begin{abstract}
Introduction: The evolution of the internet and consequently of the computer environment has led to the emergence of Web 2.0 tools, which in turn allow the active participation of users in digital processes. Objective: Identify the types of interactions occurring in blogs and social network site Facebook, between librarians and users, for promotion and improvement of services and products offered by information units,
\end{abstract}


specifically university libraries. Methodology: Scientific articles were analyzed in two different ways using a mixed approach; quantitatively with the aid of descriptive statistics for the numerical identification of those who talk about Facebook and blogs and regarding the geographical origin of the empirical fields. For the qualitative analysis, the content analysis technique was used in the interaction, use and evaluation categories for the subsequent treatment of the results. Results: The results showed that library attention regarding the Web 2.0 tools is focused on usage, followed by evaluation. Interaction with users is minimized. Conclusions: Information units are able to advertise their products and services via Internet, but they are not making use of all the potential that users have to improve their activities and processes.

Descriptors: Web 2.0. Interactivity. Information units. Social network sites. Blogs.

\title{
HERRAMIENTAS WEB 2.0 EN UNIDADES DE INFORMACIÓN: CUESTIONES DE DIVULGACIÓN Y MEJORA CONTINUA IDENTIFICADOS EN ARTÍCULOS CIENTÍFICOS
}

\begin{abstract}
RESUMEN
Introducción: La evolución de Internet y por lo tanto el entorno informático condujeron a la aparición de herramientas de la $W e b 2.0$, que a su vez permitan la participación activa de los usuarios en los procesos digitales. Objetivo: Identificar los tipos de interacciones que se producen en los blogs y la red social Facebook, entre los bibliotecarios y usuarios, para la difusión y para mejorar los servicios y productos ofrecidos por las unidades de información, específicamente las bibliotecas universitarias. Metodología: Con enfoque mixto, artículos científicos fueron analizados de dos formas. Cuantitativamente con la ayuda de estadística descriptiva para la identificación numérica de qué tratan de Facebook y de blogs y sobre el origen de los campos empíricos. Para el análisis cualitativo se utilizó la técnica de análisis de contenido en las categorías de interacción, utilización y evaluación para el procesamiento posterior de los resultados. Resultados: Los resultados mostraron que la atención por parte de las bibliotecas para las herramientas de la Web 2.0 se centra en el uso, seguido por la evaluación, siendo la interacción con los usuarios reducida. Conclusiones: Las unidades de información son capaces de divulgar sus productos y servicios a través de internet, pero no están utilizando todo el potencial que tienen los usuarios para mejorar sus actividades y procesos.
\end{abstract}

Descriptores: Web 2.0. Interactividad. Unidades de información. Sitios de redes sociales. Blogs. 